Revista de Filología Románica

ISSN: 0212-999X

http://dx.doi.org/10.5209/RFRM.58153

\title{
Alonso Zamora Vicente y Galicia
}

Carmen Mejía Ruiz ${ }^{1}$

Recibido: 20 de mayo de 2017 / Aprobado 4 de octubre de 2017

Resumen. En esta colaboración se hace un recorrido de la trayectoria profesional de Alonso Zamora Vicente vinculada a Galicia. Sus primeros años en Santiago de Compostela, sus estudios pioneros sobre los fenómenos de la dialectología gallega publicados en Argentina, sus amistades en Galicia y su itinerancia por distintas Universidades e Instituciones hasta la formación del Departamento de Filología Románica en la Universidad Complutense.

Palabras clave: Alonso Zamora Vicente; Galicia; dialectología gallega; Filología Románica.

\section{[en] Alonso Zamora Vicente and Galicia}

\begin{abstract}
This contribution explores the career of Alonso Zamora Vicente linked to Galicia. His first years in Santiago de Compostela, his pioneering studies on the phenomena of Galician dialectology published in Argentina, his friendships in Galicia and his itinerancy by different Universities and Institutions until the creation of the Department of Romance Philology at the Complutense University of Madrid.
\end{abstract}

Keywords: Alonso Zamora Vicente; Galicia; Galician dialectology; Romance Philology.

Sumario: 1. Los inicios de la relación de Alonso Zamora Vicente con Galicia. 2. Zamora Vicente, filólogo. 3. Zamora Vicente estudioso de la lengua gallega. 4. Alonso Zamora impulsor de las lenguas minoritarias. 5. Referencias bibliográficas.

Cómo citar: Mejía Ruiz, C. (2017). Alonso Zamora Vicente y Galicia, en Revista de Filología Románica 34. Núm. especial, 41-48.

\section{Los inicios de la relación de Alonso Zamora Vicente con Galicia}

La vinculación de Alonso Zamora Vicente con Galicia se inició en su juventud, ya que en el año 1942 llega al Instituto Gelmírez como catedrático procedente del Instituto de Mérida, donde empezó su investigación como dialectólogo. Mario Pedrazuela (2007:108) lo rememora de la siguiente manera:

En octubre de 1942 llegó Zamora Vicente a Santiago de Compostela como catedrático del instituto Gelmírez. Ocupó este cargo durante escaso tiempo ya que a los pocos meses, lo llamaron de Madrid para que explicara dialectología en la universidad.

$1 \quad$ Universidad Complutense de Madrid

Email: cmejiaru@ucm.es 
Su tesis, sus artículos sobre distintas hablas lo llevan al cabo de muy pocos meses como profesor de dialectología a la Facultad de Filosofía y Letras de Madrid:

Hasta entonces no existía en la facultad esta disciplina, ya que estaba unida a la fonética geográfica, por lo que resultaba difícil encontrar para explicarla un profesor solvente. El decano de la facultad, Eloy Bullón, se acordó de un joven catedrático de instituto que acababa de leer su tesis doctoral sobre "El habla de Mérida" y que había publicado varios artículos sobre el habla de Albacete y la influencia del leonés en el habla de Mérida. Contó con la aprobación de Luis Ortiz, director de Universidades en aquellos años, a quien habría hablado bien de este profesor su amigo Dámaso Alonso (Pedrazuela 2007:189).

Alarcos Llorach, que fue alumno de Zamora Vicente en ese curso de dialectología, recupera al joven dialectólogo, amante de los sonidos portadores de vida:

El don Alonso, con la insinuante y dulce tensión de sus cuerdas vocales y sus peripatéticos desplazamientos entre el estrado y pupitres, se nos puso a explicar Dialectología. [...] Fue una pena que el curso fuera sólo de un llamado cuatrimestre, porque no pudimos apenas pasar del leonés. Pero bastó para que algunos nos enterásemos de muchas cosas y de que detrás del amor por los sonidos variados, y de las palabras diversas, hubiese cosas que tocaban, se palpaban y que también desaparecían con el tiempo (Alarcos Llorach 1973).

Zamora aprovecha para preparar una cátedra de universidad a la que se presenta al año siguiente (1943) y curiosamente lo destinan a Santiago de Compostela, aunque la cátedra a la que se presenta y aprueba era para Oviedo. La cátedra la ocupa en la sección de Historia, única existente en la Facultad de Filosofía y Letras en Santiago. Por lo tanto, la cátedra es ocasional, una cátedra de circunstancias mientras llega la oportunidad de optar por otro lugar en el que existiera Románicas. En Galicia junto con el Decano de la facultad intentó que se abriera la sección de Románicas, pero fue un intento fallido.

Zamora Vicente (AA.VV. 1999:205) habla de la situación en la que estaba Galicia cuando él llegó a Santiago de Compostela:

Cuando llegué a Galicia quedaban algunas personas estudiosas. Galicia tuvo un resurgir local en los años de la República. Había unas cuantas personas universitarias que aguantaron allí. Estuvieron mucho tiempo arrinconados. Ramón Otero Pedrayo fue catedrático de Universidad hasta anteayer, Casimiro Torres, pues igual y Fraguas, el geógrafo. Estaba también Fermín Bouza, Carré Alvarellos. Gentes que habían trabajado en aquel Seminario de Estudios Gallegos. Hicieron [...] cosas de folklore, de arqueología y de historia que estaban a la altura de Madrid. También colaboraban gentes que trabajaban en Madrid y que no eran gallegos. [No existía esta cosa feísima de ahora, esa separación total entre autonomías] Hicieron trabajos estimables. Lo último que hicieron que se quedó cortado por la guerra, fue la versión y edición del Codex Calixtinus, que hizo un tal señor Hill, norteamericano. Se tradujo cuando se puso de nuevo en marcha con la estructura franquista, y el Consejo se incautó de todo aquello. Aquello funcionaba muy bien pero en el campo de la lingüística y de la oralidad no se hacía nada. 


\section{Zamora Vicente filólogo}

Zamora como filólogo empieza a publicar sus estudios de crítica literaria. En esos años publica el poema de Fernán González, existe carta laudatoria sobre este estudio de D. Ramón Menéndez Pidal al joven profesor, quien trabajó con el maestro en el Centro de Estudios Históricos en su etapa de formación universitaria. Mario Pedrazuela (2007:112-113) se detiene en la importancia de este estudio:

En su edición (Zamora Vicente, 1946) incluye, al pie del texto, los pasajes de la Primera Crónica General, que permiten establecer al lector una comparación entre el texto histórico y el poema, lo que la convierte en una edición bastante aceptable del Poema. El libro, a pesar de recibir alguna crítica exigente y precisa, como la que hizo María Rosa Lida en la Nueva Revista de Filología Hispánica (María Rosa Lida, 1949), supuso un texto definitivo - para la época- del Poema y así se lo reconoce su maestro, Menéndez Pidal, quien le agradece el esfuerzo realizado:

Querido Zamora: Con el mayor interés recibo esta edición del Fernán González, que es sin duda, la mejor que se ha hecho de tan difícil texto. Todos los recursos críticos están aprovechados en forma acertada y la anotación es precisa y muy ilustrativa. Noto solamente que a veces las correcciones de Marden están aceptadas sin indicar la lección del manuscrito. Mucho hay que agradecer a usted esta publicación y yo soy el más satisfecho teniendo aquí reunidos tantos elementos de juicio².

\section{Zamora Vicente estudioso de la lengua gallega}

Alonso Zamora volcado en la investigación y en la docencia, empieza a preocuparse por la lengua gallega ante la ausencia de estudios rigurosos, señala Zamora Vicente (AA. VV. 1999: 205):

Yo empecé a estudiar gallego porque además me distraía, primero no se sabía nada concreto. No existía más que algún trabajo bueno muy local hecho por alemanes, un señor Ebeling, del núcleo de Hamburgo y un señor Scheneider que estudió la Limia. Algunos trabajos aislados de Kruger, y luego palabrería más o menos inútil.

Gracias a la amistad con Ulpiano Villanueva Zamora recorre toda Galicia:

Tuve en Santiago un gran amigo, al que recordaré toda mi vida con verdadero cariño, que era catedrático de microbiología, un médico eminentísimo, que era más o menos de mi edad, tendría tres años más que yo, Ulpiano Villanueva. Cada vez que le llamaban de algún sitio -siempre iba cuando el enfermo estaba más en tratos con el sepulturero que con el médico- me iba con él, [y me quedé un verano entero además en Galicia, cuando los cursos] (Ibídem).

Zamora, mientras su amigo ve a los enfermos, se dedica a hablar con las gentes de los lugares. Él también está trabajando, de esas conversaciones recoge el mate-

2 Carta de Menéndez Pidal a Zamora Vicente de 16 de junio de 1946. Archivo de la Fundación Zamora Vicente (Cáceres) (Pedrazuela 2007:112-113). 
rial para realizar sus futuros trabajos lingüísticos sobre la lengua gallega. Hace lo que los filólogos llamamos trabajo de campo, el mismo Zamora Vicente (AA. VV. 1999:205-206) nos dice:

Hice una red, quizá, el doble de tupida que la del Atlas Lingüístico General de Navarro Tomás. Y estudié tres o cuatro fenómenos nada más, el sufijo - anus, la geada y el seseo. La geada es el más importante. A mí no me quita nadie de la cabeza que el límite de la geada actual es todavía el límite de dos conventos romanos y el límite de las diócesis de Braganza y Astorga. Los romanos sabían colonizar muy bien. No eran británicos, respetaban las comunidades indígenas. Que una línea sin accidentes geográficos siga siendo la misma después de los siglos, eso no lo explica Chomsky, es una cosa de matiz histórico que tiene que ver con la gente que lo habla. Cuando yo vi aquello me quedé maravilladísimo. ¡Me sentí obispo de Braganza!

Este material que recoge el filólogo durante su estancia en Galicia verá la luz fuera de España. Concretamente: La "Geografía del seseo gallego" lo hará en el número 3 de la revista Filología, que funda el propio Zamora durante su estancia en Buenos Aires en el año 1951. El estudio sobre "La frontera de la geada", el más relevante para él, se incluye en el Homenaje a Fritz Krüger en Mendoza en el año 1952. En el año 1953 en México en el volumen 7 de la Nueva Revista de Filología Hispánica lo hace el estudio titulado: "De geografía dialectal: -ao, -an en gallego". Años más tarde, 1963, publica: "Los grupos -uit-, -oit- en gallego moderno: su repartición geográfica" en el número 21 del Boletim de Filologia de Lisboa. Posteriormente, en 1986, los investigadores gallegos recogerán estos trabajos en la prestigiosa revista Verba editada por la Universidad de Santiago de Compostela.

Mario Pedrazuela (2007:112-113) con respecto a estas investigaciones de Zamora Vicente señala:

En sus estudios sobre la geada, Zamora llega a una serie de conclusiones arriesgadas, como el propio autor reconoce. Establece que la geada, fenómeno que consiste en la pronunciación sorda de la velar sonora $g$, como velar sorda fricativa, $g h, h$, entra en Galicia por los pueblos astures y su área geográfica coincide con la de la cultura de los castros.

Esta teoría, pionera en su momento, va a ser apoyada por Navarro Tomás quien, desde Nueva York, donde impartía clases en la Columbia University, felicitaba a Alonso Zamora por lo acertado de sus investigaciones:

He visto con interés sus contribuciones a la geografía lingüística gallega: frontera de la geada y de -ao - an, después de la del seseo. Todo ello está muy elaborado. Muy sugestivas sus hipótesis de sustrato, que considero bien fundadas ${ }^{3}$.

Todos estos estudios se publican, como hemos dicho, en el extranjero cuando Zamora Vicente no está en Galicia ni en España. En una carta desde Buenos Aires en 1951 escribe a Fernández del Riego: 
Mis cosas gallegas son dos. Una sobre la frontera y explicación histórica de la geada, en la que no veo, ni mucho menos, un fenómeno de vulgarismo, y unas breves notas sobre la geografía del seseo gallego... A lo mejor a los gallegos no les gusta (Alonso Montero 2007:156).

Alonso Zamora Vicente mantiene una correspondencia con uno de los galleguistas más comprometidos por aquel entonces, Francisco Fernández del Riego, quien las puso en manos del profesor Xesús Alonso Montero (2007:155), que decide publicarlas en el número 10 de Madrygal. Reproducimos un fragmento de una de ellas para se conozca al profesor Zamora Vicente y su saudade gallega:

\section{7-11-1947}

\section{Amigo Del Riego:}

Comprendo perfectamente ese escozor de que V. me habla. Pocos pueblos como el español pueden hablar de escozores y, en ocasiones, de algo más que de escozores. Pero ya pasó. Mientras les dejen en paz, menos mal. Yo muchas veces le pido a Dios allá por lo más hondo, que España se reencuentre un poco y que vuelva a tener un momento histórico lleno de sinceridad. Mientras eso no llegue no seremos nada.

Espero que los días de Santiago le hayan hecho bien. Yo tengo agravada su nostalgia de manera acuciante y permanente. ¡Tardes de la Quintana, al abrigo de la Iglesia! En estas largas, suaves, tardes de Castilla, yo evoco vivamente mi costumbre de Santiago, con don Ramón Prieto, cuesta de Bonaval arriba mientras se van cayendo las campanadas de la Catedral, o recorriendo la ciudad con Ulpiano Villanueva, en la visita a sus enfermos. En el silencio de mi biblioteca, resu[e]na dulcemente la calle enlosada, la lluvia terca, la queja de los mendigos. Santiago es un milagro vivo que no nos merecemos los españoles. Si yo fuera rico, me compraría uno de aquellos palacios, lo arreglaría por dentro para vivir y haría de su Universidad una de las mejores de Europa. Como no hay nada de eso, me conformo con soñarlo.

\section{Alonso Zamora impulsor de las lenguas minoritarias}

Zamora Vicente enferma del pulmón y por esta causa debe ausentarse de Galicia en el año 1946. Tras su recuperación se casa con María Josefa Canellada, y ocupa la cátedra de Filología Románica en Salamanca. De allí irá a Buenos Aires, Salamanca, México, Alemania, Copenhague, Estados Unidos, entre otros lugares. En esta andadura D. Alonso demuestra su espíritu abierto, innovador, dejando siempre su huella: la revista de Filología en Buenos Aires, su labor en el Colegio de México y un largo etcétera. Vuelve a Madrid en el 69 y ocupa la cátedra de Filología Románica en la Universidad Complutense y en este momento recuperamos al filólogo interesado por las lenguas minoritarias.

Don Alonso va formando el Departamento de Filología Románica como puede, pues intentaba que las lenguas románicas que no estaban adscritas a ningún Departamento estuvieran en el de Románicas; necesitaba profesores para enseñar gallego, catalán, portugués, rumano. Don Alonso narra cómo se las ingeniaba en aquellos momentos: 
Intenté traer un joven de Cataluña que se encargara del catalán, y no lo conseguimos, porque el dinero que la Facultad podía dar era muy poco y nos mandaron a la profesora Argilés. Y el gallego, ¿cómo lo teníamos arreglado? Tenía a alguien de cuando en cuando, porque teníamos muchísimo trato con el departamento de Constatino García y siempre venía alguien de allí.

Llegamos a invitar a Jorge de Sena que estaba en California, uno de los grandes escritores portugueses de ahora. Estuvo en nuestro Seminario dándonos una leccioncita. Iordan también vino, y teníamos al profesor Popovici que era rumano y muy pintoresco. [...] Luego el vasco con Pilar Muñoa, era una gran mujer [...] teníamos muy bien atendido el vasco (AA.VV. 1999:208).

Así, Alonso Zamora Vicente nos va inmiscuyendo en las lenguas románicas. Mantiene sus relaciones con Galicia y fomenta en la universidad madrileña el estudio de esa lengua y de su literatura. Xesús Alonso Montero (2007:154) en la correspondencia citada señala:

Sabe moi ben Zamora Vicente que Del Riego é un dos intelectuais galegos máis comprometidos coa causa da lingua e das Letras galegas, compromiso no que asumiu tarefas tan decisivas como a de dirixir a revista Grial, creada en 1963. Dez anos despois, varios intelectuais extragalegos (Dámaso Alonso, Tavani, Piel, Rodrigues Lapa,...) foron requeridos para opinar sobre a revista. Esta foi a resposta do noso filólogo:

\section{SIGNIFICATIVA Y EXCELENTE}

La revista Grial es verdaderamente significativa y excelente. Da fe de vida de la honda y grave preocupación intelectual de las gentes de habla gallega. Y lo hace sin localismo rancio, sino con ese aliento seguro y firme, que lleva de lo local y regional a lo universal. Puede codearse sin desdoro con las revistas de mayor empuje. Sus diversas secciones ponen sobre la mesa una tarea intensa y consciente, sin apasionamientos trasnochados, sino vestida de eficacia y verdad, que conduce, derechita, a suponer algo en el conjunto nacional. Grial ha sabido escoger el camino más llano de sentido dentro del quehacer intelectual, con sus esquinces, sus curvas peligrosillas, pero con meta segura. No es difícil percibir ya, después de los cuarenta y tantos números publicados, un fruto maduro: la dignificación de la lengua gallega como vehículo de alta cultura. Y eso, repito, sin lirismos huecos, sin rimbombancias oratorias, tan quebradizas, sino por el esfuerzo colectivo y la entrega total. Deseamos a Grial una larga vida, llena de logros, de manifestaciones brillantes que satisfagan su vocación de permanencia.

ALONSO ZAMORA VICENTE

Catedrático de Universidad

Secretario Perpetuo de la R. Academia Española

(Grial 42, 1973, p. 467)

La Universidad de Santiago de Compostela le nombra Doctor Honoris Causa en el año 1995. El profesor González Martel rememoró este momento en la necrológica que se publicó en el número 9 de la Revista de Estudios Gallegos. Madrygal: 
En el puesto, los periódicos del día notificaban que [...] la Universidad nombraría ese día a tres nuevos doctores honoris causa:

Adelantado, se encaminó por la rúa.

Por aquí, por aqui!! Es la hora de clase. Ahí... ¡Esa es mi ventana, la fiestra!... Cuántas voces, cerrada o abierta, entraban. Era un aula en anfiteatro, la número uno. La Casa donde comencé mi singladura universitaria. Realmente todo Santiago discurría por esta esquina al mercado. Cuánto aprendí (Zamora Vicente 1993, apud González Martel 2006:126).

Aquel era un ventanal de la Facultad casi a la altura misma de la voz de la calle, por donde la ciudad a diario se compenetraba con la universidad ante el jovencillo profesor.

Algunas mañanas, el bullicio de la calle penetraba por la ventana, pregones cortos, estrangulados, gritería múltiple, un sordo rumor de playa lejana que deslizaba la vida al pie de los cristales. En este local di mi primera clase universitaria en Santiago, octubre de 1943 (Ibidem).

Zamora Vicente era consciente - eso quería conseguir-, de que la universidad no era nada sin su sociedad. Apenas algo más tarde proclamaría:

En esta ocasión no tengo más remedio que, por encima de los malos humores y desencantos, pasajeros, sí, pero penosos, proclamar mi enorme fe en la Universidad. [...] Toda mi generación (de la que soy, en verdad, un superviviente) ha tenido un torcedor espiritual: soñar con una España nueva [...]. Y lo sabíamos muy bien, esto no sería posible sin una universidad también nueva, eficaz creadora de ciencia y de personalísimo talante vital. [...] De ahí mi fe en la Universidad, una fe rotunda, sin quiebros ni fisuras (Zamora Vicente 1993, apud González Martel 2006:126).

Tras el merecido título de Doctor Honoris Causa por la universidad gallega don Alonso sigue entusiasmándose con nuevos proyectos, como el de la creación de la Revista de Estudios Gallegos. Madrygal, a la que apoyó con su prestigioso nombre. Para mí, lo más gratificante fue que después de estar con mi familia en su casa un domingo de septiembre de 2005, removiera Roma con Santiago hasta dar conmigo para decirme: "Carmen, hija, sólo te llamaba para decirte que Madrygal es preciosa, que estáis haciendo una cosa muy bonita con la Filología Gallega". La satisfacción de oír al maestro decir esas palabras compensa cualquier debilidad o desánimo.

Y continuamos en ese camino, en el camino que él nos descubrió y nos ofreció generosamente, como todo lo que él hacía. En estos momentos, después de la labor que hizo Zamora Vicente para conservar el gallego en nuestra universidad tenemos, desde 1994, un profesor lector gracias al convenio existente entre la Universidad Complutense de Madrid y la Secretaría Xeral de Política Lingüística. Así, tenemos la certeza de que seguimos en la andadura del maestro, quien nos guía cotidianamente con esa frase tan suya: “QQue seas buena, forajida!”, y que nos evoca su mirada cariñosa y sabia. Esperamos que con este volumen homenaje don Alonso esté contento. Nosotros lo hemos intentado hacer lo mejor posible, siguiendo siempre su ejemplar magisterio. 


\section{Referencias bibliográficas}

AA.VV. (1999): "Entrevista a Alonso Zamora Vicente, catedrático de Filoloxía Románica e Académico da Lingua". Madrygal. Revista de Estudios Gallegos 2:201-213.

Alarcos Llorach, Emilio (1973): "Primer recuerdo de don Alonso, dialectólogo en "mi menor". Papeles de Son Armadans IX-CCX:345-349, agosto-septiembre.

Alonso Montero, Xesús (2007): "Cartas de Alonso Zamora Vicente a Francisco Fernández del Riego". Madrygal. Revista de Estudios Gallegos 10:153-157.

González Martel, Juan Manuel (2006): “Alonso Zamora Vicente, lembranza del ventanal a la calle de un aula gallega (1916-2006). Madrygal. Revista de Estudios Gallegos 9:123-129.

Lida, María Rosa (1949): "El Poema de Fernán González de Alonso Zamora Vicente". Nueva Revista de Filología Hispánica 3:182-185.

Pedrazuela Fuentes, Mario (2007): “Compostela cerca”. Madrygal. Revista de Estudios Gallegos 10:107-115.

Zamora Vicente, Alonso (1986): Estudios de dialectología hispánica. Anexo 25 de Verba. Anuario Galego de Filoloxía. Santiago de Compostela: Universidad de Santiago de Compostela.

Zamora Vicente, Alonso (1993): Compostela años atrás. Santiago de Compostela: Universidad de Santiago de Compostela. 